\title{
Anatomo-physiological features of knee injuries and possibilities of conservative treatment
}

\author{
Yulia Yurlova ${ }^{1, *}$ and Sergey Dianov ${ }^{1}$ \\ ${ }^{1}$ Astrakhan State Medical University, 414000, Bakinskaya st., 121, Astrakhan, Russia
}

\begin{abstract}
The knee joint is a complex biomechanical system, where the complexity of structure determines pathology variety, difficulties in treatment and rehabilitation. The conservative treatment possibilities of the ligamentous apparatus injuries of a knee are the subject of our discussion. Purpose of the study is to analyze the prevalence of knee traumatic injuries and modern ideas about the conservative treatment possibility of these injuries. Ligamentous apparatus injury of a knee joint is a common one, especially among athletes, with different mechanisms of knee injuries characteristic of different sports. Injuries of the lateral collateral ligament must be diagnosed in a timely manner in order to determine the possibilities of conservative and / or surgical treatment. Failure to recognize the injury details can lead instability and poor results to a knee after ligament reconstruction. Proponents of conservative treatment tactics provide evidence that non-operative treating of the ligaments also gives good results. The complex structure of a knee joint and a large number of variants of its damage impose a special responsibility on traumatologistsrehabilitologists, who are engaged in the restoration of its functions. The question of the choice between surgical restoration or conservative treatment of acute BCS injuries of knee joints remains open and depends on the specific situation, but in each case, rehabilitation measures are required, on the timeliness and adequacy of which the patient's quality of life will depend on.
\end{abstract}

\section{Introduction}

The knee joint is a complex biomechanical system, which normal functioning provides a person's activity. Epidemiological studies regarding the incidence of traumatic injuries of knee joints, types of injuries, various methods of treatment and rehabilitation, outcomes of knee joints injuries in various populations is not enough [1], even on official website of the Russian Scientific Research Institute of Traumatology and Orthopedics, named after R. R. Vreden. Although the statistics study is necessary both, for the specialized orthopedictraumatological and rehabilitation services work and, also for identifying promising areas of scientific research. Ligamentous apparatus injury of a knee joint is a common one, especially among athletes [2]. There are indications of a high frequency of joint injuries in the structure of injuries in some research works. So, according to R.M. Tikhilov et al., in

* Corresponding author: michmacha@mail.ru 
the general structure of injuries, dislocations and sprains of joints range from 14.5 / 1000 to $16.3 / 1000$ people. The authors note a tendency for an increase in the contribution of these injuries to the injuries structure, while the proportion of some other injuries types (injuries, burns, intracranial injuries, fractures of the limb bones) is decreasing [3].

Detailed epidemiological analysis of morbidity, including post-traumatic, diseases of the musculoskeletal system in the Russian Federation for 2015-2016 was carried out in the work of R.M. Balabanova et al. [4].

According to Belarusian researchers, there were for about $15 \%$ patients with knee injuries in the specialized orthopedic and traumatology department. The hospital structure of knee injuries is represented mainly by meniscus ruptures. A case histories study of the orthopedic and traumatology department in Vitebsk Regional Clinical Hospital showed that the proportion of patients with knee joint pathology was $14.8 \%$. The injuries were $42.2 \%$, diseases were $57.8 \%$. Among the patients, there were $58.6 \%$ of men, $41.4 \%$ of women. Distribution by age: $15-44$ years old were $64 \%$, 45-64 years old were $30 \%$, and over 65 years old were $6 \%$ [5].

Among the injuries, meniscus ruptures (52.2\% hospitalized) were the most often, injuries of the knee joint ligaments $(20.5 \%)$ were observed, intraarticular fractures and hemarthrosis due to bruise were less common $(13.7 \%$ each). Among the diseases of the knee joint, the leaders were gonarthrosis $(52.4 \%)$ and trauma consequences were $(18.3 \%)$, including post-traumatic contractures and instability. Meniscus ruptures are the most common knee injuries. According to V.P. Dekailo et al., they are $22 \%$ in the general pathology structure of the knee joint [5], and according to other sources, their frequency is even higher, up to $80-85 \%$ [6]. Ruptures of the meniscus inner are $86 \%$, the outer are $10 \%$, simultaneous damage to both menisci are $4 \%$ of cases. The meniscus rupture was accompanied by damage to the anterior cruciate ligament in $15 \%$ of cases, and to the posterior cruciate ligament in $2 \%$. Injuries to the knee joint ligaments are $8.7 \%$ in the structure of the knee pathology joint, $20.5 \%$ are in the structure of its traumatic injury. Injuries to the intra-articular ligaments are $44 \%$, extra-articular ligaments are $39 \%$, intrinsic ligament of the patella are $17 \%$, bruises and hemarthrosis are $5.8 \%$. Most of the consequences of knee injuries are contractures $(54.6 \%)$ that developed after intra- or periarticular fractures of the distal femur (shins), patella fractures, as well as after surgical reconstruction of the ligamentous apparatus of the knee joint. Posttraumatic instability of the knee joint is observed in $18.2 \%$ [5].

According to A.M. Belyakova et al., bones fractures that form a knee joint are $3.7-9.4 \%$, and fractures of the femur, tibia condyles are $1.5-2 \%$ of all fractures of the skeleton bones. The incidence of knee injuries ranges from 6.9 to $7.5 \%$ of all lower limb injuries. Among the internal injuries of knee joint, the most frequent are meniscus ruptures, from 32 to $85 \%$, including medial $-45-87 \%$ of cases, lateral $-3-15 \%$, both at the same time $-47 \%$, and concomitant injuries of menisci and ligamentous apparatus of the joint - from 2 to $20 \%$. Condyles fractures are $2-9 \%$ of all long bones fractures and $6-12 \%$ are of intra-articular fractures [7].

Knee injuries are often associated with a variety of sports, so they are well studied and described in the scientific literature. This is due to the fact that athletes often go beyond the normal physiology and biomechanics of the musculoskeletal system. The main mechanisms of joint damage are direct trauma and indirect shock or torsional action on the joint.

Thus, injuries of the knee joints are observed in 14-24\% of gymnasts during their sports career in artistic gymnastics. The most common injuries of joint are sprains, fracture of pineal gland, dislocation of patella or subluxation, chondral fracture, acute or chronic tendonitis, stretching of the muscle-tendon fibers. Cruciate ligament injuries are caused by injuries that occur during the dismount. Instability of the patella occurs as a result of the 
valgus traction effects, as well as external rotation during vaults, floor exercises and dismounts [8].

Skier's knee injuries result from falls to the knee, resulting in bruising, acute prepatellar bursitis, and patellar fractures. Twisting-type injuries are less common as a result of landing after difficult ski jumping. Skaters' fatigue injuries prevail: patellofemoral syndrome and inflammation of the patellar tendon [8]. Wrestler's knee joint is most often damaged and most of them occur during falls, more often in a defensive wrestler. Patellar bursitis, medial and lateral collateral ligament injuries and meniscus rupture develop, the latter are more common in wrestling than in any other sport. They arise as a result of twisting movement of the supporting limb. Collateral ligament damage, exposed to varus or valgus traction on the supporting limb during protection, are often [8].

Weightlifters' the knee joints are critical point, maintaining the position of the body in space. They are characterized by chronic pain in the knee joint, resulting from enormous stress. The reason for this is the frequent performance of maximum knee flexion under the weight of the barbell. This is because when the knee joints are flexed more than $40^{\circ}$, forces acting on the knee-hip joint become excessive. Meniscus injuries occur of weightlifters during squatting, when hallux valgus is combined with rotation of the knee joint with improper exercise technique. Jumpers' injuries develop due to a mismatch between the load and the specific viscosity of soft tissues of the knee joint. Hockey players' knee joints are in a bent position, which increases their vulnerability. In a lateral impact, external rotational loading can damage the medial collateral and anterior cruciate ligaments. As a result, recurrent instability of the knee joint occurs and the risk of meniscus rupture and damage to the articular surfaces increases. In addition, hockey players often have patellofemoral injuries, especially patellar chondromalacia, and patellar fractures as a result of direct impact [8].

Football is the most traumatic deu to sports doctors opinions. Ligaments and menisci of the knee joints are frequently damaged. The injury rate in football will increase. There are alarming trends in knee injuries, including ruptures of the anterior cruciate ligament and other injuries of the ligaments, cartilage and meniscus, post-traumatic osteoarthritis [9], but analytical studies on this topic are clearly insufficient [10].

Judo is one of the Olympic sports with the lowest injury rates. An assessment of injuries frequency among judokas during competitions $(n=26862,19-35$ years old) showed that over 15 years 699 injuries were registered, of which $2.5 \%$ required medical attention. The most frequently injured were the knee joint were $(17.4 \%)$, shoulder were $(15.7 \%)$ and elbow were (14.2\%), Sprains (42.2\%) and bruises (23.1\%) were most often diagnosed [11].

Factors predisposing to knee injuries include joint instability $(12 \%)$, decreased muscle elasticity $(11 \%)$, insufficient recovery from training loads $(17 \%)$, irregular training $(2 \%)$, poor equipment $(17 \%)$, lack of discipline and violations of the game rules $(24 \%)$, other factors and their combination (29\%) [8].

According to resources analyze, from 8 to $22 \%$ of intra-articular injuries lead to permanent disability [7, 12], despite the fact that the diagnosis and treatment of concomitant injuries of the knee joint had advanced far ahead over the past decades [13].

The complexity of the knee joint structure determines its pathology variety, difficulties in treatment and rehabilitation, as well as the causal relationship between traumatic and degenerative-dystrophic changes in the joint. The conservative treatment possibilities of the ligamentous apparatus injuries of the knee are the subject of discussion.

Purpose of the study is to analyze the conservative treatment possibilities of traumatic injuries of the knee joint. 


\section{Materials and methods}

The study involved 30 people with knee injuries due to their informed consents, (group 1: 12 people had injury to the medial collateral ligaments; group 2: 4 people had cruciate ligament injury; group 3: 14 people had combined injuries). Patient age was from 30 to 72 years, average was 55.57 years, standard deviation was $\mathrm{SD}=12.484$, men were $16(53.3 \%$, average was 51.50 years, $\mathrm{SD}=10.570)$, women were $14(46.7 \%$, average was 60.21 years, $\mathrm{SD}=13.233$ ), all patients lived in urban areas and had an average level of physical activity of no more than 2 points.

The clinical picture were complaints of pain and instability under load in the knee joint, edema, decreased muscle strength and cramps in the leg muscles, hesitating to move. Patients used anti-inflammatory nonsteroidal drugs (NSAIDs) in the form of ointments, topically (ibuprofen, diclofenac, ketoprofen, etc.) for pain syndrome treating.

Objectively positive Lachman test, rotational axis displacement test, drawer symptom in horizontal supine position, posterior drawer test decreased muscle strength. All patients underwent standard X-ray examination in frontal and lateral projections to exclude concomitant fractures [14].

The main clinical symptoms of injured knee joints were assessed before and after treatment of all patients. The points of activity level before treatment was assessed (on a scale from 0 - no active movements in the damaged joint, up to 5 - active movements in full volume), lameness (from 0 - absent, to 3 - hard), muscle atrophy (0 - no, 1 - yes), regular intake of NSAIDs ( 0 - no, 1 - yes) and average values were calculated.

The results were statistically processed using Excel for Windows, version 8 and STATISTICA 6.0.

The following basic rehabilitation measures were applied:

1. Massage of the injured limb, which included transverse massage to prevent adhesions in the muscles of the thigh and hamstrings; myofascial release (rolling out hamstrings, rolling out the quadriceps, iliotibial tract and fat pad); step-by-step study of the adductor, popliteal, gluteal muscles, from 8 to 10 sessions.

2. Physiotherapy: ultraphonophoresis of Bishofit gel on the device "UZT-1.01 F" (number in the state medical register $78 / 1261-33$ ) with a contact emitting head with an area of $4 \mathrm{sm}^{2}$, in continuous mode, labile, with a radiation intensity of $0.4-0.6$ to $1.0 \mathrm{~W} / \mathrm{sm}^{2}$ for the affected area of the joint, duration 10 minutes, 8-10 procedures.

3. Electrical stimulation of the thigh and lower leg muscles, $8-10$ procedures.

4. Daily physical education according to an individual program.

The period of the rehabilitation program was from 1 to 3 months, average -2.33 months, $\mathrm{SD}=0.479$.

\section{Results}

Assessment of the main clinical symptoms before the start of rehabilitation measures, after 1.5 months and after 2.5 months from the beginning of their implementation, showed good and excellent results (Table 1, 2, 3, 4).

Table 1. Assessment of the physical activity level of 1-3 groups before and after treatment (points).

\begin{tabular}{|l|c|c|c|c|}
\hline & \multicolumn{3}{|c|}{ Group } & \multirow{2}{*}{$\begin{array}{c}\text { Average } \\
\text { points }\end{array}$} \\
\hline & $\begin{array}{c}\mathbf{1} \\
\mathbf{n}=\mathbf{1 2}\end{array}$ & $\begin{array}{c}\mathbf{2} \\
\mathbf{n}=\mathbf{4}\end{array}$ & $\begin{array}{c}\mathbf{3} \\
\mathbf{n}=\mathbf{1 4}\end{array}$ & 1.33 \\
\hline Before starting treatment & 1.33 & 1.50 & 1.28 & 1.57 \\
\hline $\begin{array}{l}1.5 \text { months from the start of } \\
\text { treatment }\end{array}$ & 1.58 & 1.50 & 1.57 & 1.57 \\
\hline
\end{tabular}




\begin{tabular}{|l|c|c|c|c|}
\hline $\begin{array}{l}2.5 \text { months from the start of } \\
\text { treatment }\end{array}$ & 2.52 & 2.25 & 1.71 & 2.10 \\
\hline $\begin{array}{l}\text { Significance of differences between } \\
\text { first and last measurement }\end{array}$ & $\mathrm{p}<0.05$ & $\mathrm{p}<0.05$ & no/point & $\mathrm{p}<0.05$ \\
\hline
\end{tabular}

Table 2. Assessment of the lameness degree of 1-3 groups before and after treatment (points).

\begin{tabular}{|c|c|c|c|c|}
\hline & \multicolumn{3}{|c|}{ Group } & \multirow[b]{2}{*}{$\begin{array}{l}\text { Average } \\
\text { points }\end{array}$} \\
\hline & $\begin{array}{c}1 \\
n=12\end{array}$ & $\begin{array}{c}2 \\
n=4\end{array}$ & $\begin{array}{c}3 \\
n=14\end{array}$ & \\
\hline Before starting treatment & 2.69 & 2.25 & 2.15 & 2.41 \\
\hline $\begin{array}{l}1.5 \text { months from the start of } \\
\text { treatment }\end{array}$ & 1.83 & 1.75 & 1.85 & 1.81 \\
\hline $\begin{array}{l}2.5 \text { months from the start of } \\
\text { treatment }\end{array}$ & 0.75 & 1.00 & 1.18 & 1.05 \\
\hline $\begin{array}{l}\text { Significance of differences between } \\
\text { first and last measurement }\end{array}$ & $\mathrm{p}<0.05$ & $\mathrm{p}<0.05$ & $\mathrm{p}<0.05$ & $\mathrm{p}<0.05$ \\
\hline
\end{tabular}

Table 3. Assessment of the muscle atrophy degree of 1-3 groups before and after treatment (points).

\begin{tabular}{|l|c|c|c|c|}
\hline & \multicolumn{3}{|c|}{ Group } & \multirow{2}{*}{$\begin{array}{c}\text { Average } \\
\text { points }\end{array}$} \\
\hline & $\begin{array}{c}\mathbf{1} \\
\mathbf{n}=\mathbf{1 2}\end{array}$ & $\begin{array}{c}\mathbf{2} \\
\mathbf{n}=\mathbf{4}\end{array}$ & $\begin{array}{c}\mathbf{3} \\
\mathbf{n}=\mathbf{1 4}\end{array}$ & 2.23 \\
\hline $\begin{array}{l}\text { Before starting treatment } \\
\text { treatment }\end{array}$ & 2.42 & 2.50 & 2.07 & 1.87 \\
\hline $\begin{array}{l}2.5 \text { months from the start of } \\
\text { treatment }\end{array}$ & 1.73 & 1.50 & 1.93 & 0.97 \\
\hline $\begin{array}{l}\text { Significance of differences between } \\
\text { first and last measurement }\end{array}$ & $\mathrm{p}<0.05$ & $\mathrm{p}<0.05$ & $\mathrm{p}<0.05$ & $\mathrm{p}<0.05$ \\
\hline
\end{tabular}

Table 4. Assessment of pain in the whole group $(\mathrm{N}=30)$ (points on a 2-point scale).

\begin{tabular}{|l|c|c|c|c|c|}
\hline & \multicolumn{5}{|c|}{ Average score on the pain scale } \\
\hline & $\begin{array}{c}\text { at rest } \\
\text { state }\end{array}$ & $\begin{array}{c}\text { In } \\
\text { process } \\
\text { of } \\
\text { walking }\end{array}$ & $\begin{array}{c}\text { climbing } \\
\text { stairs }\end{array}$ & $\begin{array}{c}\text { going } \\
\text { down the } \\
\text { stairs }\end{array}$ & $\begin{array}{c}\text { during } \\
\text { physical } \\
\text { exertion }\end{array}$ \\
\hline Before starting treatment & 0.43 & 0.70 & 0.67 & 0.57 & 0.73 \\
\hline $\begin{array}{l}1.5 \text { months from the start } \\
\text { of treatment }\end{array}$ & 0.39 & 0.52 & 0.47 & 0.41 & 0.33 \\
\hline $\begin{array}{l}2.5 \text { months from the start } \\
\text { of treatment }\end{array}$ & 0.10 & 0.17 & 0.23 & 0.20 & 0.13 \\
\hline $\begin{array}{l}\text { Significance of } \\
\text { differences between first } \\
\text { and last measurement }\end{array}$ & $\mathrm{p}<0.05$ & $\mathrm{p}<0.05$ & $\mathrm{p}<0.05$ & $\mathrm{p}<0.05$ & $\mathrm{p}<0.05$ \\
\hline
\end{tabular}

Thus, as a result of rehabilitation measures, the level of physical activity in the damaged joints increased, the manifestations of lameness and muscle atrophy decreased, pain at rest state, walking and doing exercise decreased significantly, and the need for regular NSAID intake significantly decreased (at $\mathrm{p}<0.05$ ). Most of the patients felt completely healthy or noted a significant improvement in the functional state of the knee joint, returned to their previous physical activity, almost completely stopped taking NSAIDs, although sometimes they continued to spare the knee, walking and climbing stairs. All patients were advised to continue their individual physical activity programs and exercise complexes in the future.

\section{Discussing}


The lateral collateral ligament (LCL), or peroneal collateral ligament, are the main stabilizers of the knee joint, preventing excessive varus and posterolateral rotation. LCL injury occurs as a result of a high-energy impact on the anteromedial knee in combination with hyperextension or non-contact during varus stress and hyperextension [15].

LCL is a cord-like structure, whicht is a part of the arcuate ligamentous complex together with tendon of biceps femoris, popliteal muscle and its tendon, popliteal menisci and popliteal peroneal ligaments, oblique popliteal, arcuate and fabello-peroneal ligaments and lateral [15] calf muscles. LCL firmly connects the lateral condyle of the femur with the fibula head, performing the function of counteracting the knee varus traction and external rotation of tibia, playing the role of a joint stabilizer. When the knee is bent by more than $30^{\circ}, \mathrm{LCL}$ is weakened, in extension it is tense $[16,17]$.

According to R.J. Yaras, $25 \%$ of patients with knee pain have collateral ligament injury. Most often these are adults aged 20-34 to 55-65 years old. Injuries to the medial collateral ligaments (MCL) are more common than LCL. Isolated LCL injuries are more common among women and in contact sports [18]. Trauma results in a sprain (class I), partial rupture (class II), or complete rupture (class III) of the ligament. As a rule, LCL is injured not in isolation, but in combination with damage to the anterior cruciate ligament (ACL), posterior cruciate ligament (PCL), and posterior lateral angle (PLA) $[18,15,16]$.

The clinical picture in the acute period were complaints of pain, soft tissue edema and ecchymosis on the knee joint skin along the lateral line. Less commonly, there was a change in gait, limited mobility, paresthesia along the lateral surface, weakness and drooping of the foot $[18,15]$. Examination revealed a decrease in muscle strength, joint instability during exercise, weakness of the quadriceps femoris muscle (inability to perform a straight leg lift). Pain appeared performing a varus stress test [16]. Complaints of pain along the lateral surface of the joint, stiffness when flexing or extending to the end, weakness and instability in the joint appeared with subacute LCL injury. Later, there were complaints of nonspecific pain in the knee joint, weakening along the entire kinetic chain, instability and maladaptive movement patterns [19]. A similar clinical picture was present by our patients.

Conservative therapy of the knee ligaments injuries within the framework of the proposed rehabilitation program has shown good and excellent results. Proponents of conservative treatment tactics also provide evidence that non-operative ligament repair gives good results [20]. Thus, the assessment of the frequency of LCL injury of athletes with knee joint injury and functional outcomes after conservative treatment showed the following. Athletes (Jiu-Jitsu) confirmed by magnetic resonance imaging (MRI) after an acute knee injury, they underwent physical examination and assessment according to Lysholm and the International Knee Documentation Committee (IKDC) scale. 7 had LCL damage out of 27 patients. The average follow-up period was 41.3 months. The average IKDC scores were 94 and Lysholm scores were 92 before injury, 26 and 36 immediately after injury, 83 and 78 after 12 months of follow-up, when all patients returned to their preinjury athletic level, average time was 4.7 months. Control studies have shown complete healing of the previously documented LCL rupture [21]. The possibility of spontaneous full recovery is recognized by other researchers [22].

Conservative treatment for I and II degrees of damage consists in prescribing local cooling, unloading the joint with a compression bandage and prescribing non-steroidal antiinflammatory drugs. In case of grade III injury, the first measures are the same, but in this case, surgical intervention is required to prevent the development of the knee joint instability. Reconstructive surgery using a semi-tendinous autograft is considered the best option for treating grade III LCL injuries $[23,24]$. The optimal treatment program is selected individually after assessing the severity of the injury. 
Physical methods in the rehabilitation treatment of patients with injuries and diseases of the joints are widely used [25]. The list of rehabilitation measures for patients after surgery for damage to the ligamentous apparatus of the knee joint is quite fully set out in the Federal Clinical Guidelines developed under the leadership of Academician of the Russian Academy of Sciences, Professor of Federal State Budgetary Institution "Research Center for Traumatology and Orthopedics, named after S.P. Mironov [25]. Rehabilitation programs are addressed different types of knee instability and post-traumatic contractures. As the principles of rehabilitation programs application, an integrated approach is indicated as the basis for success, as well as the adequacy, repetition and optimality of the impacts $[24,25]$.

The scientific analysis shows that a significant number are patients with the knee joint injuries, which often occur as a result of practicing certain sports among the patients of the orthopedic and traumatological profile. Part of the intra-articular injuries of the knee joint leads to permanent disability. There are insufficient statistics on the knee injuries incidence and further research is needed due to the importance of this issue. However, the complex structure of the knee joint and a large number of its damage variants impose a special responsibility on traumatologists-rehabilitologists who are engaged in the restoration of its functions. Despite the possibility of injuries detailed diagnosis using modern MRI methods, surgical treatment is often impossible or difficult for a number of reasons. In this case, the role of conservative methods of the articular and periarticular injuries treatment increases. Our clinical observations show that conservative therapy of injuries to the ligamentous apparatus of the knee joint can be quite effective.

The choice between surgical restoration or conservative treatment of acute LCL injuries of the knee joints depends on the specific situation, but anyway, in each case, rehabilitation measures are required, which timeliness and adequacy will depend on the patient's quality of life.

\section{References}

1. Russian Scientific Research Institute of Traumatology and Orthopedics, named after R. R. Vreden, https://rniito.org

2. Korolev A.V., Afanasyev A.P., Ilyin D.O. et al., Genius of Orthopedics 26(3) (2020) DOI: http://dx.doi.org/10.18019/1028-4427-2020-26-3-413-419

3. Tikhilov R.M., Vorontsova T.N., Cherny A.Zh., Luchaninov S.S. The state of injuries and orthopedic morbidity in the adult population of St. Petersburg in 2009-2011 4(66), 110-119 (2012)

4. Balabanova RM, Dubinina TV, Demina AB, Krichevskaya OA., Scientific and practical rheumatology 56(1), 15-21 (2018)

5. Deykalo V.P., Boloboshko K.B., Surgery news 1(15), 26-31 (2007)

6. F.Sh. Bakhtiozin, Damage to the menisci of the knee joint (Publishing house of Kazan University, Kazan, 1990)

7. Belyakova A.M., Boychenko R.A., Velichko M.N. et al., Clinical guidelines for highly qualified athletes rehabilitation after surgical treatment of injuries and diseases of the lower extremities. Clinical guidelines (Moscow, FMBA of Russia, 2018)

8. I.V. Tkalich, A.A. Cherepok, Sports traumatology. Tutorial (Zaporozhye, ZSMU, 2013)

9. Roth TS, Osbahr DC, Am J Orthop (Belle Mead NJ) 47(10) (2018)

10. Vaishya R, Kambhampati Sr, Vaish Ab., Indian J Orthop 54(3), 281-293 (2020) 
11. Błach W, Smolders P, Rydzik Ł et al., J Clin Med. 10(4), 852 (2021)

12. S.M. Carek, Prim Care, 115-131 (2020).

13. Bollier M, Smith PA, J Knee Surg. 27(5), 359-68 (2014)

14. Guan Ng JW, Myint Y, Ali FM, EFORT Open Rev 5(3), 145-155 (2020) doi: 10.1302/2058-5241.5.190012

15. Recondo JA, Salvador E, Villanúa JA, Barrera MC, Gervás C, Alústiza JM., Radiographics, 91-102 (2000)

16. Logerstedt DS, Snyder-Mackler L, Ritter RC, Axe MJ, Godges JJ., Journal of Orthopaedic and Sports Physical Therapy, 1-37 (2010)

17. Grawe Br, Schroeder AJ, Kakazu R, Messer MS. J Am Acad Orthop Surg. 26(6), e120e127 (2018) doi: 10.5435/JAAOS-D-16-00028

18. R.J. Yaras, N. O'Neill, A.M. Yaish, Lateral Collateral Ligament (LCL) Knee Injuries (StatPearls, 2020)

19. E.T. Ricchetti, B.J. Sennett, G.R. Huffman, Orthopedics 31(5) (2008)

20. E.F. Temponi, A. Saithna, L. Honório de Carvalho et al., Orthop J Sports Med 7(1) (2019) doi: 10.1177/2325967118822450

21. B.A. Davis, L.P. Hiller, S.G. Imbesi, E.Y. Chang, Skeletal Radiol. 44(8), 1175-9 (2015) doi: 10.1007/s00256-015-2108-6

22. P. Kannus, Am J Sports Med 17(1), 83-88 (1989)

23. J.M. Cooper, P.T. McAndrews, R.F. La Prade, Posterolateral corner injuries of the knee: anatomy, diagnosis, and treatment. Sports medicine and arthroscopy review (2006)

24. Negodaeva E.V., Evstigneeva L.P. Sports medicine: science and practice 2, 26-33 (2011)

25. Mironov S.P., Tsykunov M.B., Builova T.V. Federal clinical guidelines (2015) 